\title{
Intestinal Microbes and Obesity: A Reality Check
}

\author{
Commentary on F.B. Morel et al.: Can Antibiotic Treatment in Preweaning Rats Alter Body \\ Composition in Adulthood? (Neonatology 2013;103:176-183)
}

\section{Michael P. Sherman}

Division of Neonatology, Department of Child Health, Women's and Children's Hospital, University of Missouri, Columbia, Mo., USA

In this issue of Neonatology, Morel et al. [1] postulated that antibiotics given to infantile rats would change the composition of the intestinal microbes and, in turn, the altered gut-related microflora would adjust metabolism leading to obesity in adult life. An animal model was used because answering the question in human infants would be long in coming. Time is of the essence because obesity is a worldwide health problem in children [2]. In the past decade, our understanding of obesity has become more lucid, and this knowledge formed the rationale for the study by Morel and colleagues. In a provocative publication, obesity was associated with the configuration of the intestinal microbiota [3]. Depending on the microbes colonizing the gut, there can be an increased harvest of energy from nondigestible carbohydrates which is then stored as fat. Gordon and colleagues extended their initial findings and defined mechanisms associated with the gut microbiota and obesity in animals and man [4-7]. A recent review summarizes how an altered intestinal microbiota results in obesity, insulin resistance and metabolic syndrome [8]. The latter article discusses how gut-related microbes influence the production of short-chain fatty acids. The effects of short-chain fatty acids on energy harvest in the intestine and their role in obesity are outlined below.
- Propionate and acetate are ligands for two G-proteincoupled receptors (GPR 41 and GPR 43) that improve energy harvest.

- Propionate and acetate also induce the release of peptide YY. Peptide YY is an enteroendocrine cell-derived hormone that normally inhibits gut motility and can accelerate intestinal transit of nutrients.

- Fasting-induced adipose factor (Fiaf) is a lipoprotein lipase (LPL) inhibitor released by enterocytes [4]. An altered intraluminal microbiota suppresses Fiaf production by gut epithelia and this results in reduced levels of this circulating LPL inhibitor, there is increased LPL activity in adipocytes, and there is enhanced storage of liver-derived triglycerides in fat cells.

- The lean phenotype observed in mice fed a high-fat diet is regulated by phosphorylation of 5 -AMPactivated protein kinase. This enzyme acts as a fuel gauge and controls cellular energy stores in muscle and liver. Intestinal microbes can increase acetate that circulates through the liver and enhances 5 -AMPactivated protein kinase activity [9].

The above points are a partial list of mechanisms related to how an altered intestinal microbiota acts on dietary nutrients to achieve a lean or obese body habitus. With the preceding mechanisms kept in mind, it is ap-

\section{KARGER}

Fax +41613061234

E-Mail karger@karger.com

www.karger.com
(C) 2012 S. Karger AG, Basel

$1661-7800 / 13 / 1033-0184 \$ 38.00 / 0$

Accessible online at:

www.karger.com/neo
Prof. Michael P. Sherman

Suite 206, Division of Neonatology, Department of Child Health

Women's and Children's Hospital, University of Missouri

404 Keene Street, Columbia, MO 65201 (USA)

E-Mail ShermanMP@health.missouri.edu 
propriate to evaluate the research design used by Morel et al. [1] and to understand why specific outcomes were achieved. In a litter consisting of 8 animals, 1 pup received amoxicillin from 5 days through 15 days of life, another pup received a placebo over the same period, and the remaining 6 animals were not treated. The investigators used the polymerase chain reaction to identify microbes known to colonize the distal bowel of rats [10]. The first analysis of the fecal microflora was performed at 21 days of age and revealed that amoxicillin-treated pups had a significant reduction in the numbers of total bacteria, Lactobacillales, Bacteroides spp., bacteria in the Clostridium leptum cluster and Methanobacteriales. By 28 days of life, treated, placebo-treated and nontreated animals had no differences in the composition of their fecal microflora, and this finding persisted for the remainder of the investigation. Moreover, body weight, relative weight of fat pads, lean body mass, and plasma leptin concentrations did not vary among amoxicillin-treated, placebotreated, and normal rats when they reached adult life.

The following points discuss how early, prolonged antibiotic use in an infantile rat model may not have resulted in an obese adult rat.

- Physiologic age equivalence of an infantile animal model should closely match its human counterpart. In this study, the rats received amoxicillin over a period that spanned a human age that ranged from preterm birth ( 32 weeks of gestation) through about 6 months of age [11]. This duration of amoxicillin therapy is longer than a standard clinical course of antibiotics. Since the change in intestinal microbiota was not sustained with amoxicillin-related biotherapy, other factors had to be operative in this model $[10,12]$. These factors remain poorly understood.

- During this type of research, it is ideal to create an intestinal microbiota in a rodent model that is comparable to that found in the human gut $[10,12]$. Obese mice are reported to have a $50 \%$ reduction in the abundance of Bacteroidetes and a proportional increase in Firmicutes compared to a lean mouse [4]. Thus, it would have been appropriate to examine whether the fecal microflora of amoxicillin-treated rat pups on the 15 th day of life mirrored the aforementioned prevalence of Firmicutes.

- Two broad-spectrum antibiotics compared to amoxicillin alone [13] might have resulted in a different outcome because dual antibiotic therapy results in an intestinal microflora with reduced bacterial diversity, a suppression of Bacteroidetes, and a preponderance of Firmicutes. Additionally, human infants treated with

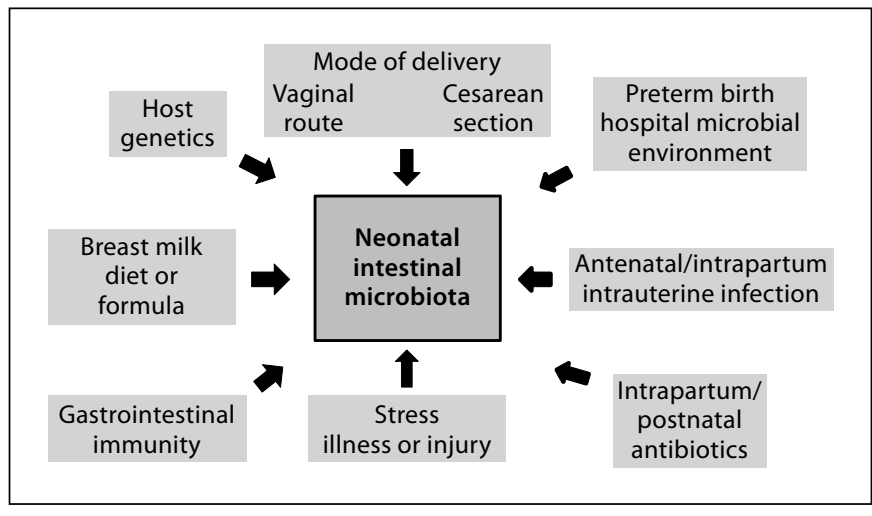

Fig. 1. Factors that modulate the development of the intestinal microbiota in human neonates.

antibiotics are known to have prolonged alterations in their intestinal microbiota [14]. There is no evidence that either of these pathophysiologic states occurred. If these intestinal conditions were present, it may have promoted obesity in later life.

- Changes in the fecal microbiota of amoxicillin-treated pups may have been different from those desired by the researchers. The reason an ideal intestinal microbiota may not have been created after amoxicillin therapy is explained in the following way. Antibiotic-treated rat pups were kept in the same litter box as nontreated animals. Rat pups in a litter box defecate into the bedding, the fecal material then adheres to the skin or fur of all animals, and a skin to oral transfer of fecal microbes occurs among littermates. In other words, the effect of amoxicillin may have been less because of fecal transplant from nontreated animals to the antibiotic-treated pups.

- Many investigators would have used next-generation technology, like pyrosequencing, to comprehensively define the fecal microbiota of infantile rats $[13,14]$. During this study, the method used to characterize the microbiota in the rodent intestine probably did not yield a comprehensive overview of all microbes present in the developing gut.

- Amoxicillin administration during the breast-feeding period might not have the same effect on the intestinal microbiota compared to antibiotic treatment during a later period of life, namely when the diet is rich in plant polysaccharides. Thus, the scientific design likely had lower concentrations of short-chain fatty acids in the distal bowel, and this scenario did not create a colonic milieu wherein energy harvest and fat storage would be enhanced. 
Lastly, figure 1 shows factors that modulate the development of the intestinal microbiota in human neonates [14]. The complexity involved in the emergence of an intestinal microbiota after birth suggests that antibiotics alone may be insufficient to program the host for obesity during adult life. A more complex diet consisting of plant polysaccharides along with an altered intestinal microbiota may be major elements associated with obesity. Morel and colleagues are correct in saying that establishing an animal model that predisposes neonates to obesity as adults is problematic. Inventing a relevant neonatal model that facilitates obesity in adults will be difficult compared to past animal models that established antenatal steroids and surfactant replacement as therapies before clinical trials began. Caregivers must appreciate that there is a substantial body of published information that shows that an altered intestinal microbiota and a specific diet may be a cause of obesity. Most of this documentation involves experiments performed in animal models. Human studies showing that obesity is influenced by microbes in our intestines means health care professionals must stay alert and look for new information in this thought-provoking field of science.

\section{Acknowledgments}

This work was supported by NIH grant R44 HD057744 and a Gerber Foundation grant.

\section{Disclosure Statement}

No conflicts of interest.

\section{References}

1 Morel FB, Oosting A, Piloquet H, Oozeer R, Darmaun D, Michel C: Can antibiotic treatment in preweaning rats alter body composition in adulthood? Neonatology 2013;103: 176-183.

2 Cali AM, Caprio S: Obesity in children and adolescents. J Clin Endocrinol Metab 2008; 93(suppl 1):S31-S36.

>3 Bäckhed F, Ding H, Wang T, Hooper LV, Koh GY, Nagy A, Semenkovich CF, Gordon JI: The gut microbiota as an environmental factor that regulates fat storage. Proc Natl Acad Sci USA 2004;101:15718-15723.

-4 Ley RE, Bäckhed F, Turnbaugh P, Lozupone CA, Knight RD, Gordon JI: Obesity alters gut microbial ecology. Proc Natl Acad Sci USA 2005;102:11070-11075.

5 Bäckhed F, Manchester JK, Semenkovich CF, Gordon JI: Mechanisms underlying the resistance to diet-induced obesity in germ-free mice. Proc Natl Acad Sci USA 2007;104:979-984.
6 Turnbaugh PJ, Hamady M, Yatsunenko T, Cantarel BL, Duncan A, Ley RE, Sogin ML, Jones WJ, Roe BA, Affourtit JP, Egholm M, Henrissat B, Heath AC, Knight R, Gordon JI: A core gut microbiome in obese and lean twins. Nature 2009;457:480-484.

7 Turnbaugh PJ, Gordon JI: The core gut microbiome, energy balance and obesity. J Physiol 2009;587:4153-4158.

$>8$ Tilg H, Kaser A: Gut microbiome, obesity, and metabolic dysfunction. J Clin Invest 2011;121:2126-2132.

-9 Carvalho BM, Guadagnini D, Tsukumo DM, Schenka AA, Latuf-Filho P, Vassallo J, Dias JC, Kubota LT, Carvalheira JB, Saad MJ: Modulation of gut microbiota by antibiotics improves insulin signaling in high-fat fed mice. Diabetologia 2012;55:2823-2834.
10 Alpert C, Sczesny S, Gruhl B, Blaut M: Longterm stability of the human gut microbiota in two different rat strains. Curr Issues Mol Biol 2008; 10:17-24.

-11 Tucker AM, Aquilina K, Chakkarapani E, Hobbs CE, Thoresen M: Development of amplitude-integrated electroencephalography and interburst interval in the rat. Pediatr Res 2009;65:62-66.

12 Gootenberg DB, Turnbaugh PJ: Companion animals symposium: humanized animal models of the microbiome. J Anim Sci 2011; 89:1531-1537.

13 Cho I, Yamanishi S, Cox L, Methé BA, Zavadil J, Li K, Gao Z, Mahana D, Raju K, Teitler I, Li H, Alekseyenko AV, Blaser MJ: Antibiotics in early life alter the murine colonic microbiome and adiposity. Nature 2012;488: 621-626.

14 Johnson CL, Versalovic J: The human microbiome and its potential importance to pediatrics. Pediatrics 2012;129:950-960. 